\section{Brief Exposure to Boiling Water Combined with Cold-moist Stratification Enhances Seed Germination of New Jersey Tea}

\author{
J. Ryan Stewart ${ }^{1,3}$ and Irene McGary ${ }^{2}$
}

AdDitional Index words. Ceanothus americanus, prairie, restoration, buckthorn, Rhamnaceae, california lilac, scarification

SUMMARY. Although there is increasing interest in propagating prairie plants native to the midwestern United States for managed and natural landscapes, several species, including new jersey tea (Ceanothus americanus), are difficult to germinate from seeds. New jersey tea, which is an attractive, compact woody shrub, is found in high-quality prairie remnants throughout the tallgrass prairie region. Developing a protocol to increase the uniformity of seed germination in this species would allow for more widespread horticultural cultivation of this stress-resistant, nitrogen-fixing species. We hypothesized that the germination response of seeds of new jersey tea would be enhanced by replicating conditions that mimic their natural environment, which included treatments under controlled conditions exposing seeds to chilling temperatures, sulfuric acid, and boiling water. Two minutes of exposure to boiling water followed by 60 days of cold-moist stratification at $4^{\circ} \mathrm{C}$ resulted in the highest germination percentage ( $48 \%)$ and mean daily germination $(2.18$ seeds/day).

Scarification with $98 \%$ sulfuric acid for 15 min followed by 60 days of cold-moist stratification resulted in significant, but lower levels of germination percentage than seeds exposed to boiling water and cold-moist stratification. Cold-moist stratification in darkness and in an 18-hour photoperiod at $4^{\circ} \mathrm{C}$ did not stimulate germination to a level suitable for production purposes. However, tetrazolium tests indicated that $79 \%$ of the seeds were viable. We conclude that cold-moist stratification should be used with boiling-water or acid-scarification to uniformly produce germinated seedlings of new jersey tea. However, nonresponsive seeds should not be discarded because they may germinate in later years if kept under appropriate conditions.

$\mathrm{P}$ ublic interest has increased in recent years in propagating prairie plant species native to the midwestern United States (Hitchmough et al., 2005). However, most assemblages of prairie species in managed landscapes and restored prairies generally are comprised of species that germinate and establish easily such as big bluestem (Andropogon gerardii), indian grass (Sorghastrum mutans), canada wild rye (Elymus canadensis), purple coneflower (Echinacea purpurea), grey-headed coneflower (Ratibida pinnata), blackeyed susan (Rudbeckia hirta), and wild bergamot (Monarda fistulosa) (Diboll, 2005; Nuzzo, 1978). These species represent only a fraction of the species currently found in high-quality prairie remnants in the midwestern United States (Polley et al., 2005). Difficulty in satisfying complex dormancy mechanisms in these species, including new

${ }^{1}$ Department of Crop Sciences, University of Illinois at Urbana-Champaign, 1011 Plant Sciences Laboratory MC-634, 1201 South Dorner Drive, Urbana, IL 61801

${ }^{2}$ Department of Natural Resources and Environmental Sciences, University of Illinois at Urbana-Champaign, 1102 South Goodwin Avenue, Urbana, IL 61801

${ }^{3}$ Corresponding author. E-mail: rstewart@illinois.edu. jersey tea, which is an attractive, compact, nitrogen-fixing, woody shrub species, remains an ongoing limitation in enabling uniform propagation for nursery-level production.

Once widely distributed throughout the tallgrass prairie region of the midwestern United States, new jersey tea populated dry to mesic prairies and open woods (Swink and Wilhelm, 1994). In addition to attractive perfect white flowers borne in panicles (Dirr, 1998), plants exhibit lustrous green foliage. Combined with difficulty in collecting seeds due to the forceful ejection of ripe seeds from capsules when fully ripe (McMillan Browse, 1994), sexual propagation of new jersey tea is notably challenging. Seeds of new jersey tea have hard, waterimpervious seedcoats similar to other members of Rhamnaceae (Frett, 1989; Keogh and Bannister, 1994), which appear to impose a form of physical dormancy. Also, ecosystems in which several congeners of new jersey tea are native, are dependent on fire for renewal and regeneration (Keeley, 1991; McMillan Browse, 1994), which is reflected in the observation that seed germination of several ceanothus ( $\mathrm{Ce}^{-}$ anothus spp.) is enhanced by being subjected to dry heat (McMillan Browse, 1994), which may increase the permeability of the seedcoat to water imbibition to allow for subsequent germination.

Satisfying physiological dormancy requirements may also be a factor in successful propagating new jersey tea via seeds. McMillan Browse (1994) observed that seeds of several ceanothus species required up to $60 \mathrm{~d}$ or longer of chilling at $5{ }^{\circ} \mathrm{C}$ to germinate. However, seeds of some species of ceanothus only have physical dormancy and thus only require scarification to germinate (Quick, 1935; Quick and Quick, 1961). Keeley (1991) did not consider seeds of ceanothus species to be sensitive to light for induction of germination.

We hypothesized the germination response of new jersey tea seeds would be enhanced if placed under conditions that mimicked their natural environment. Our objective was to determine the germination percentage and rate of daily germination of seeds randomly subjected to cold stratification with and without light, boiling water, and acid scarification.

\section{Materials and methods}

Seeds for this experiment, which had been harvested when fully ripe in Sept. 2007, were purchased on 17 Oct. 2007 from Prairie Moon Nursery in Winona, MN. Seeds were stored in dry conditions at $4{ }^{\circ} \mathrm{C}$ until the initiation of the experiment.

The experiment was set up in a completely randomized design with five treatments and five replicates per treatment. Each experimental unit consisted of 50 seeds placed between two pieces of 90 -mm-diameter filter paper within a $100 \times 15-\mathrm{mm}$ plastic petri dish. The first treatment was a control

\begin{tabular}{llll}
\hline $\begin{array}{l}\text { Units } \\
\begin{array}{l}\text { To convert U.S. to SI, } \\
\text { multiply by }\end{array}\end{array}$ & U.S. unit & SI unit & $\begin{array}{l}\text { To convert SI to U.S., } \\
\text { multiply by }\end{array}$ \\
\hline 25.4 & inch(es) & Mm & 0.0394 \\
$\left({ }^{\circ} \mathrm{F}-32\right) \div 1.8$ & ${ }^{\circ} \mathrm{F}$ & ${ }^{\circ} \mathrm{C}$ & $\left(1.8 \times{ }^{\circ} \mathrm{C}\right)+32$
\end{tabular}


where experimental units were placed in a dark growth chamber at $25{ }^{\circ} \mathrm{C}$ for $60 \mathrm{~d}$. The second treatment was a coldmoist stratification treatment where experimental units were placed in a dark growth chamber at $4{ }^{\circ} \mathrm{C}$ for $60 \mathrm{~d}$. The third treatment was a cold-moist stratification treatment where the experimental units were placed in a growth chamber with an 18-h daily photoperiod at $4{ }^{\circ} \mathrm{C}$ for $60 \mathrm{~d}$. In the fourth treatment, seeds were exposed to $98 \%$ sulfuric acid $\left(\mathrm{H}_{2} \mathrm{SO}_{4}\right)$ for $15 \mathrm{~min}$ and were then placed in a dark growth chamber at $4{ }^{\circ} \mathrm{C}$ for $60 \mathrm{~d}$. In the fifth treatment, seeds were boiled at $90{ }^{\circ} \mathrm{C}$ for $2 \mathrm{~min}$, rinsed immediately in an icewater bath, and inserted into a dark growth chamber at $4{ }^{\circ} \mathrm{C}$ for $60 \mathrm{~d}$.

Before treatment initiation on 21 Dec. 2007, each experimental unit received $2.0 \mathrm{~mL}$ of distilled water. Petri dishes were checked periodically and water was added as needed. Tetrazolium tests (Peters, 2000) were performed on 10 Jan. 2008 on two replications of 100 seeds each to get an estimate of their viability. The period for each treatment ended on 18 Feb. 2008. Experimental units from each treatment were subsequently moved into a $25{ }^{\circ} \mathrm{C}$ dark growth chamber with those in the control treatment. Experimental units were then checked daily for germination for $20 \mathrm{~d}$. Germination was defined as the emergence of a radicle that could be viewed without magnification.

Data analysis. The effects of each treatment were analyzed by using the generalized linear model procedure of SAS/STAT (v. 9.2, SAS Institute, Cary, NC), which is a statistical procedure commonly used to analyze categorical data (Littell et al., 2002). Parameters were estimated by using the option for negative binomial distribution and using the log link function. Mean estimates of germination percentage and mean daily germination were obtained by the least squares means option. Multiple comparisons were used post hoc to determine which treatments were significantly different.

\section{Results}

Tetrazolium tests indicated that $79 \%$ of the seeds were viable. Seeds of new jersey tea treated with boiling water germinated at the greatest percentage and rate among all treatments (Table 1). Although seeds in the acidscarification treatment germinated 25\% less and had nearly half the daily rate

Table 1. Measures of germination of new jersey tea. Values for treatments are percentages and means of five multiseed replications. Except for the control treatment, each treatment was subjected to $60 \mathrm{~d}$ of cold-moist stratification at $4^{\circ} \mathrm{C}\left(39.2^{\circ} \mathrm{F}\right)$ followed by $20 \mathrm{~d}$ in a $25^{\circ} \mathrm{C}\left(77.0^{\circ} \mathrm{F}\right)$ growth chamber to allow germination to occur. Seeds in the control treatment were in a dark $25^{\circ} \mathrm{C}$ growth chamber for $80 \mathrm{~d}$.

\begin{tabular}{lcc}
\hline Treatment & $\begin{array}{c}\text { Germination percentage } \\
{[\text { mean } \pm \text { SE }(\%)]}\end{array}$ & $\begin{array}{c}\text { Daily germination } \\
{[\text { mean } \pm \text { SE }(\text { seeds } / \mathrm{d})]}\end{array}$ \\
\hline Boiling water with cold stratification & $48 \pm 2.0 \mathrm{a}^{\mathrm{z}}$ & $2.18 \pm 0.10 \mathrm{a}$ \\
Sulfuric acid with cold stratification & $23 \pm 2.0 \mathrm{~b}$ & $1.05 \pm 0.10 \mathrm{~b}$ \\
Cold stratification with photoperiod & $8.0 \pm 2.0 \mathrm{c}$ & $0.36 \pm 0.10 \mathrm{c}$ \\
Cold stratification in darkness & $5.0 \pm 2.0 \mathrm{~cd}$ & $0.23 \pm 0.10 \mathrm{~cd}$ \\
Control & $0.0 \pm 2.0 \mathrm{~d}$ & $0.00 \pm 0.10 \mathrm{~d}$ \\
\hline
\end{tabular}

${ }^{\mathrm{z}}$ Means within each column with the same letter are not different at $P \leq 0.05$ according to the least squares means comparison procedure of the generalized linear model.

of germination than of those in the boiling-water treatment, their response was higher than of those in the coldstratification and control treatments (Table 1). While the cold-stratification treatment with a photoperiod elicited a greater germination percentage and mean daily germination than the control treatment, there were no differences between the cold stratification treatment in darkness and the control treatment (Table 1 ).

\section{Discussion}

Sixty days of cold-moist stratification under dark conditions combined with 2 -min exposure to $90^{\circ} \mathrm{C}$ boiling water enhanced germination of seeds of new jersey tea, which resulted in $48 \%$ more germination than seeds in the zero-response control treatment (Table $\mathrm{I}$ ). It is assumed exposure to heat creates fissures in the otherwise impervious seedcoat, allowing water to penetrate (McMillan Browse, 1994). McMillan Browse (1994) reported satisfactory levels of seed germination in several ceanothus species exposed to hot water. Keeley (1987) indicated that direct exposure of seeds of ceanothus species in the California chaparral to fire did not result in appreciable levels of germination. However, radiative heat transfer through the soil into the seed bank of ceanothus species under natural conditions appears to be required to stimulate germination (Keeley, 1987). Although short exposure to $\mathrm{H}_{2} \mathrm{SO}_{4}$ elicited a significant level of seed germination (Table 1), it may be considered beneficial for a grower that boiling water, which is simpler and safer, induces higher levels of germination.

If a subsample of untreated new jersey tea seeds had $79 \%$ viability, why did only $48 \%$ of the seeds germinate in the boiling water treatment? Although seeds often lose viability while under storage conditions (Hartmann et al., 2002), seeds of several species of ceanothus are known to have considerable longevity (Quick and Quick, 1961). McMillan Browse (1994) reported that ceanothus seeds stored in dry, cool conditions persisted for 12 to 15 years with little or no deterioration in viability. Moreover, seeds tested for viability in our study were in dry, cool storage for less than $14 \mathrm{~d}$ before viability testing, which we assume did not negatively impact seed health. This behavior likely reflects a survival strategy of new jersey tea similar to that of other native prairie species (Johnson and Anderson, 1986) and other ceanothus species (Keeley, 1987) where seeds accumulate in a dormant seed bank in fire-prone ecosystems and sporadically germinate over long periods of time when exposed to environmental cues (Telewski and Zeevaart, 2002) such as heat induced by grassland fires. Also, considering the possible longevity of new jersey tea seeds, nongerminating seeds should not be discarded, but should likely be stored under appropriate conditions to allow for germination to occur in later years.

Although cold-moist stratification stimulates seed germination of some species within Rhamnaceae (Keeley, 1991; Stewart and Graves, 2005), our results indicate that supplemental scarification is required to elicit uniform germination for production purposes. It also appears that while cold-moist stratification alone did not elicit relatively high levels of germination, daily cycles of an 18-h photoperiod plus cold-moist stratification induced levels of germination that were higher 
than seeds only cold-moist stratified. Cold-moist stratification, whether in darkness or supplemented with light radiation, should be used with boiling water or acid scarification to induce seed germination of new jersey tea for use in managed or natural landscapes. Also, given the relatively low rate of mean daily germination, which is a measure used to determine the uniformity of seed germination, in all treatments (Table 1), sufficient numbers of seeds should be collected to ensure target seedling numbers are reached. However, it should be considered that seeds may not have been collected at full maturity or cold-stratified long enough to elicit optimal germination response given winters in the midwestern United States are generally longer than $60 \mathrm{~d}$. Further research into improving seed germination of new jersey tea should possibly include longer cold-stratification periods and possibly treatments of scarification not combined with accompanying cold-moist stratification. Given that seeds with hard seedcoats requiring acid scarification to induce germination offer require exposure to acid for $30 \mathrm{~min}$ or more (Baskin and Baskin, 2001), pretreating new jersey tea seeds to longer periods than 15 min of $\mathrm{H}_{2} \mathrm{SO}_{4}$ exposure should be included in future experiments.

\section{Literature cited}

Baskin, C.C. and J.M. Baskin. 2001. Seeds: Ecology, biogeography, and evo- lution of dormancy and germination. Academic Press, San Diego.

Diboll, N. 2005. Designing seed mixes, p. 135-150. In: S. Packard and C.F. Mutel (eds.). The tallgrass restoration handbook. Island Press, Washington, DC.

Dirr, M.A. 1998. Manual of woody landscape plants: Their identification, ornamental characteristics, culture, propagation, and uses. Stipes Publishing, Champaign, IL.

Frett, J.J. 1989. Germination requirements of Hovenia dulcis seeds. HortScience 24:152.

Hartmann, H.T., D.E. Kester, F.T. Davies, and R.L. Geneve. 2002. Hartmann and Kester's plant propagation: Principles and practices. Prentice Hall, Upper Saddle River, NJ.

Hitchmough, J., E. Reid, and A. Dourado. 2005. Establishment and persistence of field sown North American prairie grasses in southern England in response to mulching and extensive weed management. J. Environ. Hort. 23:101-108.

Johnson, R.G. and R.C. Anderson. 1986. The seed bank of a tallgrass prairie in Illinois. Amer. Midl. Nat. 115:123-130.

Keeley, J.E. 1987. Role of fire in seed germination of woody taxa in California chaparral. Ecology 68:434-443.

Keeley, J.E. 1991. Seed germination and life history syndromes in the California chaparral. Bot. Rev. 57:81-116.

Keogh, J.A. and P. Bannister. 1994. Seed structure and germination in Discaria toumatou (Rhamnaceae). Weed Res. 34: 481-490.
Littell, R., W.W. Stroup, and R. Freund. 2002. SAS for linear models. Wiley, Hoboken, NJ.

McMillan Browse, P. 1994. The propagation of Ceanothus from seed. New Plantsman 1:218-219.

Nuzzo, V. 1978. Propagation and planting of prairie forbs and grasses in southern Wisconsin, p. 182-189. In: D.C. GlennLewin and R.Q. Landers (eds.). Fifth Midwest Conf. Proc., Iowa State University, Ames.

Peters, J. 2000. Tetrazolium testing handbook: Contribution no. 29 to the handbook on seed testing. Assn. Offic. Seed Analysts, Lincoln, NE.

Polley, H.W., J.D. Derner, and B.J. Wilsey. 2005. Patterns of plant species diversity in remnant and restored tallgrass prairies. Restor. Ecol. 13:480-487.

Quick, C.R. 1935. Notes on the germination of Ceanothus seeds. Madrono 3:135140 .

Quick, C.R. and A.S. Quick. 1961. Germination of Ceanothus seeds. Madrono 16: 23-30.

Stewart, J.R. and W.R. Graves. 2005. Seed germination of Rhamnus caroliniana: Implications for ecology and horticulture. HortScience 40:767-770.

Swink, F. and G. Wilhelm. 1994. Plants of the Chicago region. Indiana Acad. Sci., Indianapolis.

Telewski, F.W. and J.A.D. Zeevaart. 2002. The 120-yr period for Dr. Beal's seed viability experiment. Amer. J. Bot. 89: 1285-1288. 